\title{
THE APPLICABILITY OF THE CENTENO, CHAUDHARY AND LOPEZ REPAIR TIME STANDARD METHODOLOGY IN A RAIL MAINTENANCE ENVIRONMENT
}

\author{
K.O. Rommelspacher ${ }^{1}$ \& C.J. Fourie ${ }^{2^{*}}$ \\ Industrial Engineering Department \\ Stellenbosch University, South Africa \\ ${ }^{1}$ kartr@sun.ac.za, ${ }^{2}$ cjf@sun.ac.za
}

\begin{abstract}
The establishment of labour standards within a production environment has become common practice, and is receiving growing recognition in the maintenance environment. However, the application of labour standards in a transit maintenance organisation has received limited attention. Centeno, Chaudhary and Lopez have developed a repair time standard methodology that has been applied in the transit bus maintenance facilities of three agencies in central Florida in the USA. An investigation into the applicability of this methodology in a rail maintenance environment in South Africa forms the basis for this study.
\end{abstract}

\section{OPSOMMING}

Die skepping van arbeidstandaarde binne 'n produksie-omgewing het algemene praktyk geword, en ontvang dit groeiende erkenning in die onderhoudsomgewing. Maar die toepassing van arbeidstandaarde binne ' $n$ vervoer onderhoudsorganisasie het tot dusver beperkte aandag ontvang. Centeno, Chaudhary en Lopez het ' $\mathrm{n}$ tyd standaard metode ontwikkel wat toegepas is in die busvervoeronderhoudfasiliteite van drie agentskappe in sentrale Florida in die VSA. 'n Ondersoek na die toepaslikheid van hierdie metode binne 'n spooronderhoud omgewing in Suid-Afrika vorm die grondslag vir hierdie studie.

1 The author was enrolled for an M Eng (Industrial) degree in the Department of Industrial Engineering, University of Stellenbosch

* Corresponding author 
The establishment of standard times to measure labour productivity in maintenance environments has always been a complex matter in industry. Traditionally, labour productivity is the sum of use values produced (products or material services) per worker employed in material production. Labour productivity is always calculated with reference to some unit of time [1]. However, in maintenance - just as in the service industry productivity cannot be as easily measured as it is in the manufacturing environment, where it can be quantified as finished products per hour, or assemblies per hour, to mention just two. As lan G. Smith [2] points out, thgere are serious problems of measurement not only on the input side of the productivity equation, but also in measuring the outputs. This is particularly apparent in the service industry, where the difficulty with measuring outputs is that the products are generally not physical units but something intangible, and are qualitative rather than quantitative.

A specific sector of the service industry is the transit industry. This industry can be split into two primary groups that focus either on the transportation of goods or the transportation of people. The passenger transit sector has particular challenges that are intrinsically linked to humans, and that are primarily revealed in people's expectations of safety, convenience, and comfort. In order to maintain high levels of all three aspects, transit companies need to pay particular attention to the comfort, reliability, and availability of their services. These expected levels of performance are sustained by rigorous maintenance. In order to achieve the expected level of quality of service consistently, the maintenance activities need to attain and maintain a specific standard, both in quality and in timeliness.

Maintenance activity measurement is the process of establishing a standard method and time that expresses quality and quantity of work output expected from a specific amount of labour or machine activity input. By comparing the actual time with the standard time, the industrial engineer can measure performance against a standard. And standards are met by taking actions to analyse variance and correct its root causes. Through this measurementcontrol process, management achieves control and continuous method improvement [3].

In order to assist in the development of maintenance standard times in transit organisations, Centeno, Chaudhary and Lopez developed a repair time standard (RTS) methodology [4]. The applicability and capability of this methodology in the rail transit maintenance industry are investigated in this study.

\section{LITERATURE REVIEW}

The methodology used to measure maintenance work performance that is aimed at improving labour productivity is to establish standards, specifically time standards. These have traditionally been defined as the time required by an average skilled operator to perform a specified task, working at a normal pace, using a prescribed method, and allowing for personal needs such as fatigue and delay. Time standards, work standards, and standards of all types have generally been applied in manufacturing. In maintenance work, however, the use of time standards needs to be applied more intricately. In this literature review, three areas are discussed. The basic building blocks and concepts for the development of time standards form the basis of the first part. In the second, the basic maintenance concepts relevant to the transit industry are discussed. Finally, the RTS methodology, which was developed specifically to establish standard times in the maintenance environment, is considered.

\subsection{The general process for the generation of standard data}

The most important principle in standard data development is that the approach is critical to the results. Useful and accurate standard data will result only from taking the right development approach. Development must follow a closely controlled process, with a significant amount of the effort devoted to up-front design and testing. Various processes 
have been developed, but very few of them for transit maintenance. In general, these processes consist of the following elements [3]:

1. Analyse the current maintenance system, listing all the maintenance categories or strategies, and summoning the relevant maintenance manuals, procedures, and work instructions.

2. Subdivide these maintenance strategies into activities by operation - a process called 'activity analysis'. This consists of the maintenance work breakdown structure, as well as the resource breakdown structure, and their relationships.

3. Use some form of application analysis to understand the final product, define the database logic, and design the application tools.

4. Analyse the standard data. This stage entails breaking down the activities further into work elements or descriptions of a measurable nature.

5. Measure the final work elements and calculate the standard times.

6. Validate the standards - a process through which actual times can be checked against the set standards. Any required changes may be identified and rectified in this stage, and sample standards can be developed.

7. Apply and maintain the system. This calls for continuous improvement.

Two key elements in establishing standard times are time studies, which are used to establish normal times, and allowances, which serve to make the establishment of the standard as fair as possible. These are now discussed in greater detail.

\subsubsection{Time studies}

For ease of measurement, the maintenance operation should be divided into groups of motions known as elements. These elements are documented in the maintenance procedures as the work or task instructions. There are two techniques that can be used to record the elemental times during the study: the continuous timing method, and the snapback technique.

Since time study is a sampling procedure, the observations can be assumed to be distributed normally about an unknown population mean with an unknown variance. Using the sample mean $\bar{x}$ and sample standard deviation $s$, the following statistical equation can be used to determine the number of observations required to gather reliable data to set standards [5]:

$n=\left(\frac{t s}{k \bar{x}}\right)^{2}$

The variable $t$ is obtained from the $t$-distribution curve, and $k$ is the desired acceptable fraction of $\bar{x}$. This calculation method is used in combination with expert opinion in the industry, accounting for the set time frame of the entire project and the perceived necessity of the number of observations. Alternatively, information taken from the Time Study Manual of the Erie Works of the General Electric Company can be used as an approximate guide to the number of cycles to observe [5]. This information is shown in Table 1.

The first step in beginning a time study is to select the operator with the assistance of the departmental or line supervisor. In general, an operator who is average or somewhat above average enables a more satisfactory study than a low-skilled or highly superior operator. The average operator usually performs the work consistently and systematically. That operator's pace will tend to be approximately in the standard range, making it easier for the time study analyst to apply a correct performance factor [5].

The actual time required to perform each element of the study depends to a great degree on the skill and effort of the operator. Therefore, it is necessary to adjust the time of a good operator upwards and the time of a poor operator downwards to a standard level. A fair and impartial performance rating should thus be the result. The basic principle of 
Table 1: Recommended number of observation cycles [5]

\begin{tabular}{|c|c|}
\hline Cycle time (min) & Recommended number of cycles \\
\hline 0.10 & 200 \\
\hline 0.25 & 100 \\
\hline 0.50 & 60 \\
\hline 0.75 & 40 \\
\hline 1.00 & 30 \\
\hline 2.00 & 20 \\
\hline $2.00-5.00$ & 15 \\
\hline $5.00-10.00$ & 10 \\
\hline $10.00-20.00$ & 8 \\
\hline $20.00-40.00$ & 5 \\
\hline $40.00-$ above & 3 \\
\hline
\end{tabular}

performance rating is to adjust the mean observed time (OT) for each element performed during the study to the normal time (NT) that would be required by the qualified operator to perform the same work:

$N T=O T \times \frac{R}{100}$

In this equation, $\mathrm{R}$ is the performance rating of the operator expressed as a percentage, with 100 per cent being standard performance by a qualified operator.

\subsubsection{Allowances}

No operator or maintenance employee can maintain a standard pace every minute of the working day. Three classes of interruptions can take place, for which extra time must be provided. The first is personal interruptions, such as trips to the restroom or water cooler. The second is fatigue, which can affect even the strongest individual doing the lightest work. The third is unavoidable delays such as tool breakage, supervisor interruptions, slight tool trouble, and material variations - all of which require that some allowances be made. Since the time study is conducted over a relatively short period, and since foreign elements should have been removed when determining the normal time, an allowance must be added to the normal time to arrive at a fair standard that can reasonably be achieved by the operator.

The time required for a fully qualified, trained operator to perform the operation - working at a standard pace and exerting average effort - is termed the standard time (ST) for that operation. The allowance is typically given as a fraction of normal time, and is used as a multiplier equal to $1+$ allowance [5]:

$S T=N T+N T \times$ allowance $=N T \times(1+$ allowance $)$

The above variables are recorded on a time observation form for later analysis in a spreadsheet program such as Microsoft Excel.

The results of the activity sampling and time study will form the basis of the maintenance standards development. After the standards have been defined, a system for measuring labour productivity against the set standards can then be effectively designed.

\subsection{Basic maintenance principles}

The basic principles and concepts in the field of maintenance are shown in Figure 1, which is an adaptation of the diagram developed by Vlok [6]. Of the three primary strategies, 


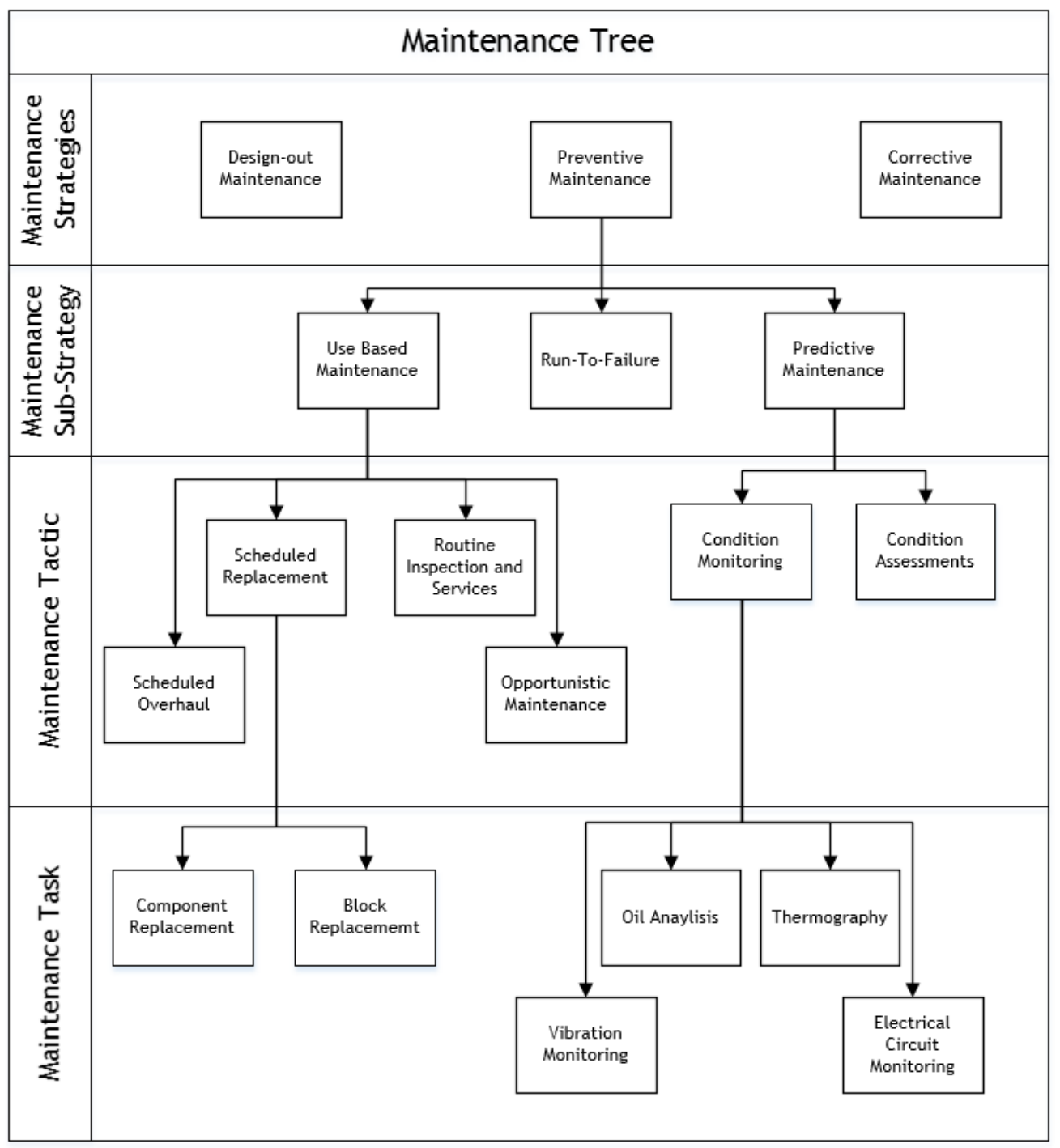

Figure 1: Basic principles and concepts of maintenance

preventive maintenance forms the largest body of knowledge of maintenance. It is also the area of maintenance that is most important to sustain a transit system that achieves a level of quality of service expected by commuters with the current vehicle fleet.

\subsection{Repair time standard methodology}

Centeno, Chaudhary and Lopez developed the RTS methodology as a more precise and detailed method than various other studies that had previously been conducted [4]. These included studies by Paaswell, Audenaerd and Jafta; Schiavone; Inba and Crittenden; and

Hill. Their intention was also to develop a methodology that was more robust than that of Venezia. Further capabilities that are claimed for this method are that it reduces total job completion time, its ability to determine capacity requirements, and its ability to monitor technician performance levels [4]. The RTS development cycle is shown in Figure 2. A more detailed description of each step forms the remainder of this section. 


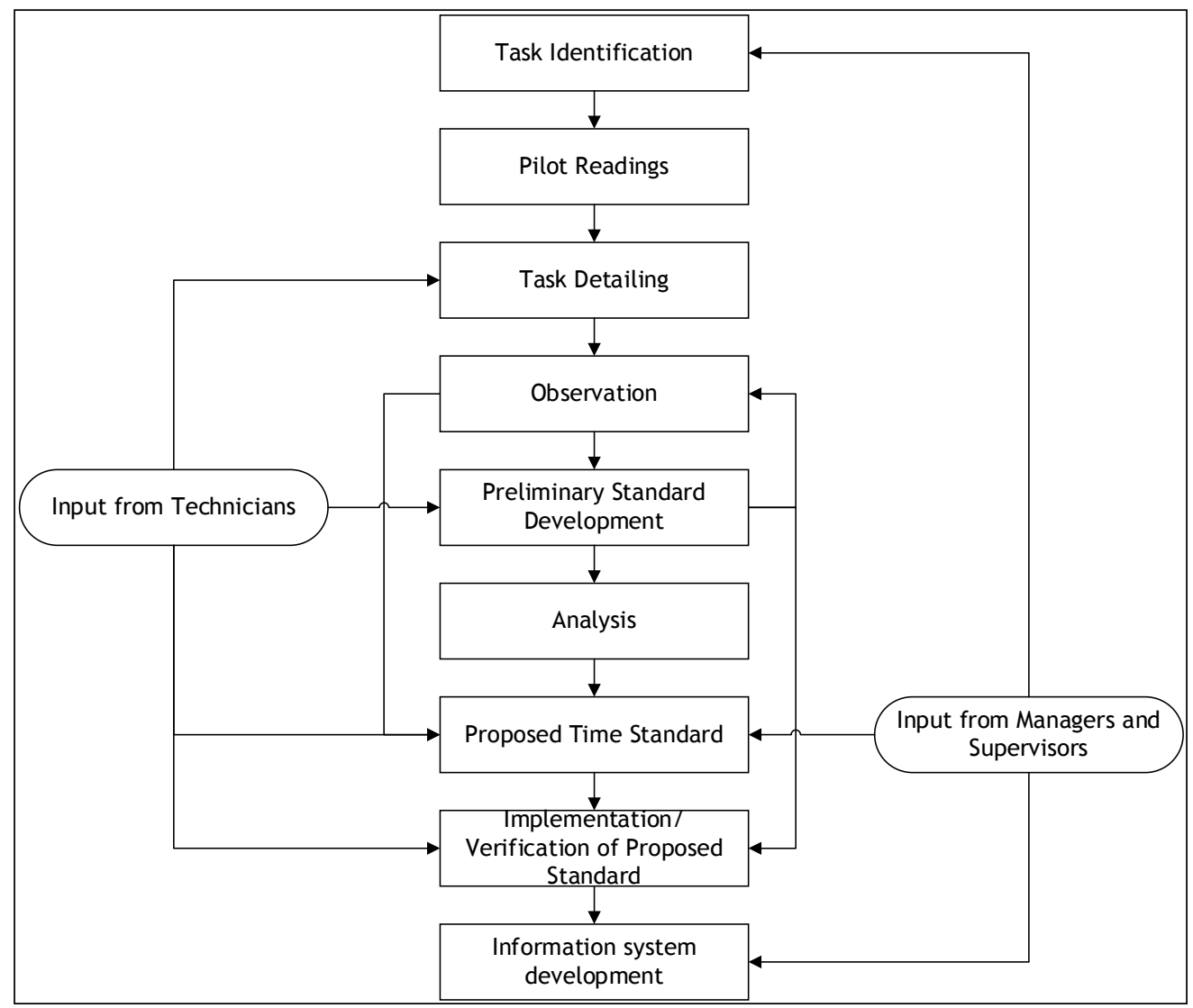

Figure 2: The RTS methodology development cycle [4]

\subsubsection{Task identification}

The critical task or system that is to be investigated is identified. The selection can be based on the repair priority, as indicated by the transit facility. One of the factors that can be taken into consideration for the selection is the frequency of service or tasks, where component failures result in extensive risks and significant losses.

\subsubsection{Pilot readings}

These readings allow the analyst to become acquainted with the process being investigated. At first, five to ten observations are performed in order to gauge the total time required to perform that task. With the primary readings, the actual number of observations required can either be calculated using equation 1; or they can be selected from a predetermined list of cycle time - number of observation ratios, such as shown in Table 1. During this step, the existing written documentation - such as procedures and checklists - is gathered, analysed, and compared with the tasks identified in Step 1. This expedites the process of accurately developing an improved process flow.

\subsubsection{Task detailing}

This step involves identifying the major processes within each task as well as the elements within each process. Elements are the smallest unit contained in a process, and are usually classified into five groups: operation, transport, inspection, delay, and storage. This classification provides valuable information for the selection and removal of unnecessary elements. Based on all this information, a time study worksheet template can be developed.

\subsubsection{Observations}

When conducting the time studies, the following guidelines should be used: 
- $\quad$ Observer experience is required in order to promote objectivity

- $\quad$ All tasks are to be performed at normal working pace, with multiple observations of the same employee to ensure consistency.

- In order to allow for external factors, the observation should be conducted at different times of the day or in different shifts.

- No special arrangements are to be made in order to achieve standards under normal conditions.

- $\quad$ Based on the experience of the observer, a performance rating is to be awarded to indicate the pace of the employee conducting the task.

\subsubsection{Preliminary standards development}

Once the predetermined number of observations have been collected, the work flow should be examined, and the best practices of different employees, workshops, and facilities should be used to create a homogeneous flow. During the analysis, redundant elements and delaying elements should be removed or improved. All the valid observations - as well as the normal times - for each element are combined to develop preliminary standard times.

\subsubsection{Analysis}

Based on the comparison and compilation of the recorded observations, an improved procedure for the facility is developed. During this process, the foreign elements should be taken into account and the times containing them removed so that they are not used to calculate the standard times. Foreign elements are generally described as unexpected events that are not part of the regular procedure. The remaining times are averaged to establish the normal time. As with the preliminary standards, the observations are evaluated, with elements that cause delays either being removed or improved. As part of the improved layout from the preliminary standard development, the process flow surrounding each task needs to be improved.

\subsubsection{Final time standard development}

Using the normal time from the analysis, and taking into account all the relevant allowances, a proposed time standard is developed. Allowances account for normal delays, such as restroom breaks or being interrupted by senior personnel. Allowances that are particularly relevant to maintenance activities in the transit industry are:

- Personal allowance

- Basic fatigue allowance

- Standing allowance

- Intermittent loud sound allowance

- Tediousness allowance

\subsubsection{Implementation and verification of proposed time standards}

Employees should be informed about and receive training for the new work flow as well as the proposed time standard. New observations are then made of employees working at a normal pace, and the recorded times are compared with the proposed times for consistency. Any large deviations will lead to the observation and analysis steps being repeated.

\subsubsection{Information system development}

In order to enforce, monitor, and manage the new time standards, a suitable information system is required. This should aid in decision-making about the employees, the process, and the resources required.

\section{APPLICATION OF THE RTS METHODOLOGY IN METRORAIL SOUTH AFRICA}

Metrorail is the state-owned company that operates all suburban passenger trains in South Africa. Maintenance activities take place in each of the large metropolitan regions. Standard times for the maintenance tasks are required in order to establish more precise costing and to predict accurately the period of time trains would be out of service. 


\subsection{Rail maintenance operations overview}

Train set maintenance consists of five different maintenance activities. The first part of the preventive maintenance (PM), known as scheduled maintenance, takes place in a twoweekly cycle. There are three levels of PM: Passenger Safety \& Comfort (known as an Ashed), Intermediate Scheduled Maintenance (known as a B-shed) and Full Scheduled Maintenance (known as a C-shed). The sequence for these three levels of PM is generally Ashed - B-shed - A-shed - C-shed, which is then repeated. The tasks involved during these PM activities include inspections, cleaning of components, lubrication, and re-calibration in order to assess the condition of the components on the train set. If during these inspections it is established that the components are no longer fit for service, they are exchanged. If these components are small enough to be exchanged by hand, this is done right away. If the components are large and need to be exchanged using specialised equipment, that coach is either removed from the trainset and replaced with another one, or that entire trainset is removed from operations until the components on the coach can be replaced. Similarly, if the interior of any of the coaches of a trainset is no longer in a suitable state for passengers, and the repairs cannot be done during scheduled maintenance, then the coach is removed from the trainset and replaced with another one, or the entire set is removed from operational service [7].

The exchange of large components on train coaches is planned by the planning office, and takes place in a separate workshop, known as the reliability workshop, from the scheduled maintenance. According to the plan, coaches are shunted into the reliability workshop, where the components are removed and replaced with new or refurbished ones. This is the second maintenance activity.

If the coach has been removed from the train set due do interior deficiencies, it is moved to the coach building workshop, as per maintenance plan from the planning office, where dedicated interior refurbishment takes place. Work performed at the coach building workshop is classified as the third maintenance activity.

The fourth and fifth activities are similar in concept, and only differ in the size of the components they work with. They involve the refurbishment of any of the components that were removed and replaced, either during the scheduled maintenance activities or during activities at the reliability workshop. The small components workshop refurbishes the smaller components, and the large components workshop refurbishes the larger components.

\subsection{RTS implementation}

Tasks were selected from four of the five different groups of maintenance activities: scheduled maintenance, reliability workshop maintenance, small component maintenance, and large component maintenance. The detailed operating procedures (DOP) for all the tasks that take place in each of these areas were drawn from the configuration office and analysed to gain a detailed understanding of the task. The DOPs were used to identify the processes that make up each task, as well as the elements that make up each process. For the scheduled maintenance area, the DOPs have already been broken down into processes and listed on check sheets. These check sheets are used in every scheduled maintenance activity, with the number of processes differing for the A-, B-, and C-sheds. The number of tasks and processes per maintenance area are shown in Table 2.

Table 2: The number of DOPs and processes per area of application

\begin{tabular}{|l|c|c|}
\hline Area of application & Number of DOPs/check sheets & Number of processes \\
\hline Large components & 23 & 145 \\
\hline Small components & 17 & 116 \\
\hline Reliability workshop & 16 & 109 \\
\hline Scheduled maintenance & 8 & 241 \\
\hline
\end{tabular}


Pilot readings were undertaken to establish how many observations would be required for each task, in order to set standard times that are statistically accurate.

From the pilot readings it was established that not all the processes of a task are performed when that task is undertaken. The primary reason for this is that many components are only exchanged if their condition warrants it, not according to a pre-determined cycle. This is chiefly relevant to the scheduled maintenance tasks. Every time a train set receives an A-, $\mathrm{B}$-, or C-shed service it is inspected, lubricated, and cleaned. If during the inspection the condition of the components is assessed as no longer suitable, those components need to be changed. Thus no task has an exact number of processes, which means that standard times cannot be set for each task, which in turn means that a standard time cannot be determined for the entire maintenance event. It was thus decided to establish standard times for each process, as when a process occurs it always has the same elements.

\subsection{Implementation results}

A specific observation period was selected, and all the processes that took place during that period were observed. Processes that did not take place during that period could not be observed. Preliminary time standards were established for each of the processes that was observed. During the observation period a significant number of foreign elements were observed, such as the non-availability of tools and replacement components, as well as an insufficient manpower for tasks that require more than one maintainer. It was also discovered that many tasks, and thus processes, can be performed by a varying number of personnel, and that the number of personnel performing a task impacted on the sequence of the processes and on the time taken to complete a process.

Preliminary standards were developed for processes that met the following criteria:

- $\quad$ Only a fixed number of individuals could perform the process;

- The process did not contain any possibility of variation;

- The process could be observed a sufficient number of times to satisfy statistical requirements.

\section{LIMITATIONS AND CAPABILITIES OF THE RTS METHODOLOGY}

The challenges experienced during the pilot readings and observations led to the process of establishing time standards in a rail transit maintenance environment to be questioned. Based on this investigation, various limitations of the RTS method were formulated. The first is that there are no specific limitations that are highlighted by the method itself. It also does not highlight in which circumstances it would be applicable to use the RTS method and in which not. The assumptions made by the RTS method are also not highlighted. From a maintenance perspective, specific limitations exist. Process variation is not taken into account, which is particularly relevant when opportunistic maintenance or any condition-based maintenance takes place.

Although standard times for individual processes can be developed, a standard time for any task that consists of varying processes cannot be established.

As standard times cannot be established for all tasks, a standard total job completion time cannot be calculated. Thus it also cannot be established how much the total job completion time has been reduced once RTS has been applied. It is also unlikely that the RTS method alone can be used to determine capacities.

\section{RECOMMENDED IMPROVEMENTS TO THE RTS METHODOLOGY}

In order for the RTS methodology's capability claims and its actual abilities to correlate better, the following alterations should be investigated. The frequency of a specific process can be used to determine the probability of that process taking place. Using the probability 
of a process occurring, an average expected task time can be developed. In order for the probability of a process being used to be calculated, sufficient data needs to be available or needs to be collected. Data collection and analysis should form part of the RTS process, as proposed in Figure 3.

Based on the limitations discussed in Section 4, the development of a specific application scope needs to be considered. This scope should outline the suitable areas of application and the relevant capabilities in that area. In its current form RTS is ideally suited for UseBased PM, excluding opportunistic maintenance. Use-Based PM includes routine inspections and set servicing, as well as scheduled replacement and scheduled overhaul. RTS is also suited to condition assessments and to any task where the processes that make up that task are fixed.

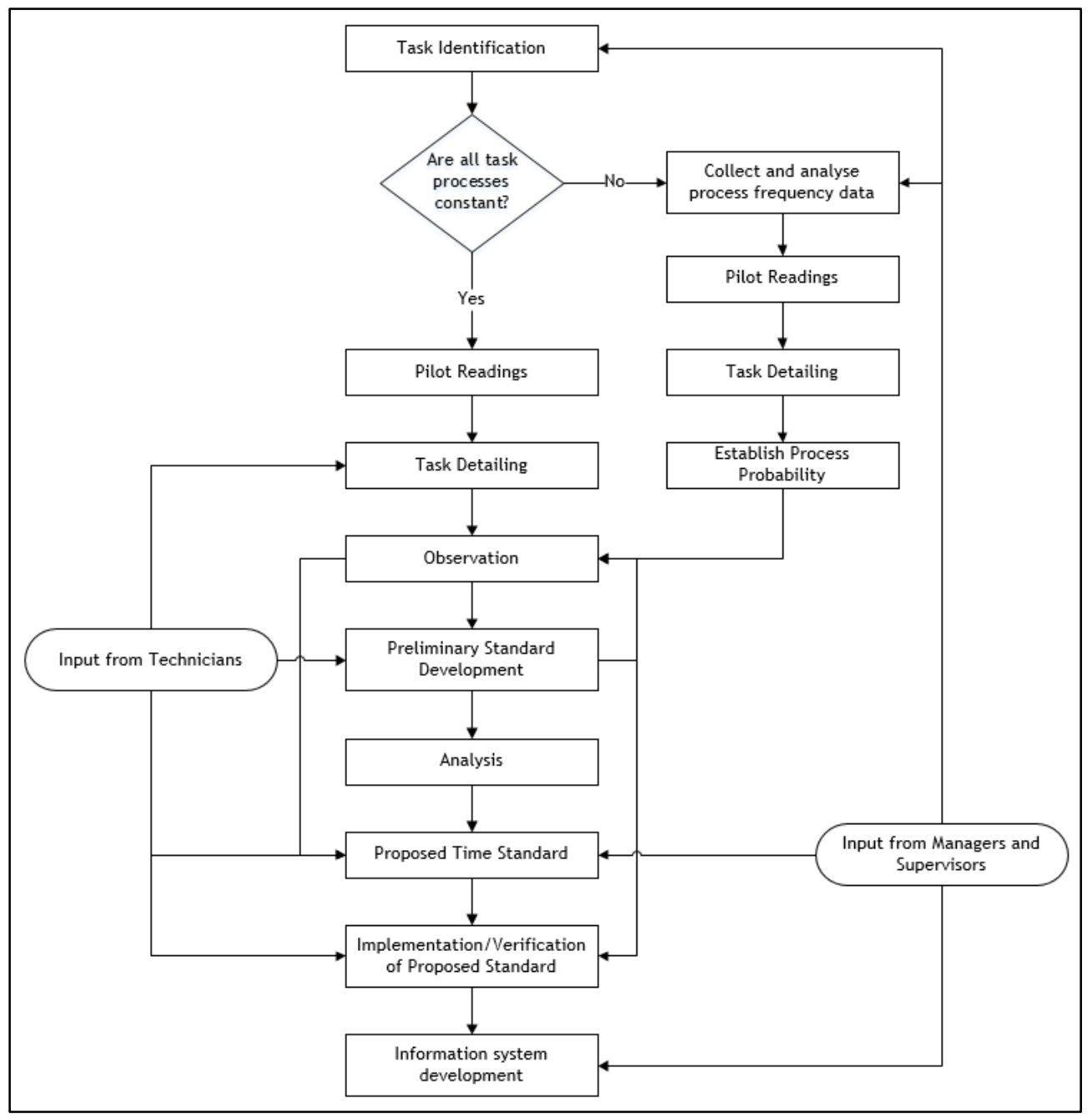

Figure 3: The proposed changes to the RTS process

\section{CONCLUSION}

Establishing standard times for a maintenance process in the rail transit industry is possible with the RTS methodology. However, there are some circumstances in which the RTS methodology is not ideally suited in its current form. Based on the findings from the establishment of standard times within Metrorail's maintenance activities, specific 
improvements to the RTS methodology were developed. The most significant proposed alteration involves developing average task times based on the probable occurrences of each of the processes that make up that task. These improvements need to be applied in practice to establish their validity, and should form part of further work.

\section{REFERENCES}

[1] Dunlop, J.T. \& Diatchenko, V.P. 1964. Labour productivity, McGraw-Hill, New York.

[2] Smith, I.G. 1973. The measurement of productivity, Gower Press, Surrey, United Kingdom.

[3] Zandin, K.B. 2001. Maynard's industrial engineering handbook. McGraw-Hill, New York.

[4] Centeno, G., Chaudhary, R. \& Lopez, P.. 2005. Developing standard times for repair activities for transit vehicles, Journal of the Transportation Research Board, 1927, pp. 112-122.

[5] Frievalds, A. 2009. Niebel's methods, standards and work design, McGraw Hill, New York.

[6] Vlok, P.J. 2011. Introduction to practical statistical analysis of failure time data: Long term cost optimisation and residual life estimation. Unpublished course notes, Stellenbosch.

[7] Rommelspacher, K.O. 2013. The recommendation and validation of an appropriate physical asset management policy for Prasa's Metrorail division, Stellenbosch University. 